\title{
Symbolic Attributes and Organizational Attractiveness: The moderating effects of applicant personality
}

\section{Bert Schreurs*, Celina Druart**, Karin Proost*** and Karel De Witte*****}

*Faculty of Economy \& Management, Hogeschool-Universiteit Brussel, Stormstraat 2, 1000 Brussels, Belgium,bert.schreurs2@hubrussel.be and Department of Social and Organizational Psychology, Utrecht University, Heidelberglaan 1, P.O. Box 80.140, 3508 TC Utrecht, The Netherlands

**Department of Data Analysis, Ghent University, Henri Dunantlaan 1, 9000 Ghent, Belgium

****Faculty of Psychology, Open Universiteit Nederland, Valkenburgerweg 177, P.O. Box 2960, 6401 DL Heerlen, The Netherlands

****Research Group for Work, Organizational and Personnel Psychology, University of Leuven, Tiensestraat 102, 3000 Leuven, Belgium

The present study examined the moderating influence of the Big Five personality factors in the relationship between five symbolic, trait-based inferences about organizations (Sincerity, Excitement, Competence, Prestige, and Ruggedness) and organizational attractiveness. Drawing on the similarity-attraction paradigm, six hypotheses were formulated, stating that the relationship between trait-based inferences and organizational attractiveness would be stronger for persons who perceive the organization as similar to them. Results of moderated regression analyses on data from a sample of 245 prospective applicants for the Belgian military revealed two significant two-way interactions, showing that Sincerity was positively related to organizational attractiveness only for individuals high on Conscientiousness, and that the relationship between Excitement and organizational attractiveness is more positive for individuals high on Openness to Experience. Practical implications, strengths and limitations, as well as directions for further research are presented.

\section{Introduction}

$\mathrm{T}$ raditionally, recruitment research has focused on instrumental job and organizational attributes, such as salary, location, size, and type of industry, as major determinants of applicants' attraction to organizations (Highhouse, Zickar, Thorsteinson, Stierwalt, \& Slaughter, 1999; Lievens, Decaesteker, Coetsier, \& Geirnaert, 2001; Turban \& Keon, 1993). These attributes are called instrumental because they primarily trigger interest among applicants due to their utility (Lievens \& High- house, 2003). Recently, there is a growing awareness that, besides instrumental attributes, applicants are attracted to organizations on the basis of symbolic attributes that they associate with a particular organization (Highhouse, Thornbury, \& Little, 2007; Lievens \& Highhouse, 2003; Slaughter, Zickar, Highhouse, \& Mohr, 2004). These attributes describe the job/organization in terms of subjective, personality trait-based characteristics. For example, applicants may be attracted to an organization because it offers good pay (instrumental), but also because it is perceived as innovative and exciting (symbolic). 
Numerous studies (e.g., Bretz, Ash, \& Dreher, 1989; Bretz \& Judge, 1994; Cable \& Judge, 1994; Chatman, 1989) have shown that individuals differ in their attraction to certain job and organizational characteristics. Until now, research adopting this interactionist perspective has primarily concentrated on how individual differences (e.g., personality, values, goals, needs) moderate the relationship between instrumental job and organizational characteristics and applicant attraction. Little research has investigated the interaction between these individual differences and symbolic job and organizational attributes. Yet, studying this interaction is important as it may assist organizations in changing their image as a strategy to attract those considered most desirable in the labor force (Rynes \& Barber, 1990). Accordingly, several recruitment scholars (e.g., Lievens, Van Hoye, \& Schreurs, 2005; Slaughter et al., 2004) have called for research on the interaction between applicants' characteristics and their perceptions of the organization's symbolic attributes. The present study responded to this call by examining the moderating role of the Big Five personality factors in the relationship between symbolic attributes and applicant attraction.

\section{The instrumental-symbolic framework}

Drawing on conceptualizations from marketing literature (e.g., Keller, 1993), Lievens and Highhouse (2003) developed the instrumental-symbolic framework for recruitment. The basic premise of this framework is that applicants assign both instrumental and symbolic attributes to jobs and organizations, comparable to how consumers associate both instrumental functions and psychological (symbolic) meanings with a brand (Katz, 1960; Keller, 1993, 1998; Shavitt, 1990). Instrumental functions refer to product-related attributes. They describe the product in terms of objective, physical, and tangible attributes that enable consumers to maximize rewards and minimize punishments. Symbolic meanings, on the other hand, correspond to nonproduct-related attributes, described in terms of subjective, abstract, and intangible attributes. Consumers assign symbolic meanings to products to maintain their self-identity, to enhance their self-image, or to express themselves (their beliefs, their traits, and their personality) (Aaker, 1997, 1999; Highhouse et al., 2007; Katz, 1960; Shavitt, 1990).

Returning to a recruitment context, an abundance of studies has demonstrated the influence of applicants' perceptions of instrumental job and organizational characteristics (e.g., pay, job security, location) on applicant attraction (e.g., Cable \& Graham, 2000; Lievens et al., 2001; Turban \& Keon, 1993). These characteristics are objective, concrete, and factual attributes of a job or organization, and trigger interest among applicants because of their utility. More recently, Lievens and Highhouse (2003) suggest that applicants are attracted to jobs/organizations not only on the basis of tangible and functional features of jobs/organizations, but also because of the meanings that applicants ascribe to the hiring organization in terms of personality traitbased inferences (e.g., exciting, innovative). In support of their argument, several studies (e.g., Lievens \& Highhouse, 2003; Lievens, Van Hoye, \& Anseel, 2007; Lievens et al., 2005; Slaughter et al., 2004) have demonstrated that applicants reliably and meaningfully ascribe symbolic meanings in terms of personality trait-based inferences to organizations. Across these studies, several, predominantly five, higher-order factors emerged. Each of these factors is delineated by several so-called facets, a term stemming from personality psychology, that provide both depth and breadth for each factor. The first factor, Sincerity, is defined by the facets downto-earth, honest, and wholesome. The second dimension, Excitement, also known as innovativeness, encompasses the facets daring, spirited, exciting, and imaginative. Competence, the third factor, stands for the facets reliable, secure, intelligent, and successful. Sophistication, also called style or prestige, is the fourth dimension, and refers to the facets upper class, trendy, and charming. Finally, Ruggedness is characterized by facets as outdoorsy, masculine, and thorough.

Moreover, Lievens and colleagues (Lievens, 2007; Lievens \& Highhouse, 2003; Lievens et al., 2007; Lievens et al., 2005) have shown that symbolic attributes are an important predictor of applicants' attraction to the organization as a place to work. Their results even indicate that, in early recruitment stages, symbolic attributes are at least as important as instrumental job and organizational attributes in predicting organizational attractiveness (e.g., Lievens, 2007; Lievens \& Highhouse, 2003; Lievens et al., 2005). Similarly, Slaughter et al. (2004) observed significant relationships between various organizational personality dimensions and organizational attractiveness. Given these past findings, an intriguing question now is whether the effect of symbolic attributes on organizational attractiveness is the same for all applicants, or that, alternatively, the effect differs according to the characteristics of the applicants. The latter can be expected based on principles of interactional psychology.

\section{An interactionist perspective on organizational attractiveness}

According to interactional psychology (Lewin, 1935), behavior is a function of the interaction between personal and situational characteristics. Applied to a recruitment context, organizational attractiveness is 
suggested to be a function of characteristics of the applicant and characteristics of the job/organization. Specifically, based on the similarity-attraction paradigm (Byrne, 1971), it can be argued that organizations who are perceived similar vs dissimilar to oneself will be more vs less attractive as a place of employment. The similarity-attraction paradigm is closely related to social identity theory (Tajfel \& Turner, 1986), which posits that individuals determine their social identity by categorizing themselves and others, and attaching value to different social categories. As individuals strive to maintain consistent identities (Steele, 1988), evaluating similar others more favorably than dissimilar others is one way to maintain a positive identity. The similarityattraction paradigm elaborates on this idea by positing that individuals who are similar will be interpersonally attracted, or in the context of organizations, that individuals are more attracted to jobs and/or organizations with certain characteristics they perceive to match their own (Ehrhart \& Ziegert, 2005).

There is ample evidence supporting the similarityattraction paradigm. For example, studies have demonstrated that the effect of pay level, mix, and system (e.g., Cable \& Judge, 1994; Lievens et al., 2001; Turban \& Keon, 1993), human resource systems (Bretz \& Judge, 1994), geographical dispersion (Turban \& Keon, 1993), centralization, and organization size (Lievens et al., 2001; Turban \& Keon, 1993) on organizational attractiveness depends on the applicants' preferences, values, goals, and personality, such that applicants are more attracted when the perceived job/organization's characteristics are consonant with the applicants' characteristics.

As becomes apparent from this overview, much research attention has been directed at how the effect of instrumental, as opposed to symbolic, job/organizational characteristics is moderated by applicants' characteristics. Much less research has investigated how the effect of symbolic characteristics, in terms of personality trait-based inferences, on organizational attractiveness depends on applicants' characteristics, perhaps due to the relative newness of the instrumental-symbolic framework. However, several earlier studies (e.g., Cable \& Judge, 1996; Chatman, 1989; Judge \& Bretz, 1992; Judge \& Cable, 1997; O'Reilly, Chatman, \& Caldwell, 1991) have addressed the puzzle of how applicants' characteristics interact with (non-instrumental) job/organizational characteristics from a related, yet distinct, perspective. Specifically, these studies investigated the fit or congruence between the recruiting organization's characteristics and the applicants' characteristics in terms of values, and its relationship with applicant attraction. In general, these studies show that high-value congruence is positively related to applicant attraction. Organizational values, however, are distinct from personality trait-based symbolic characteristics (Judge \& Cable, 1997). Values, relative to personality, are less stable over time. Furthermore, the personality of an organization may be inferred on the basis of limited information, whereas an accurate assessment of the organization's values is likely to require a great deal of more information (Slaughter et al., 2004).

Taken together, the present study aims at examining to what extent the effect of symbolic, personality traitbased characteristics ${ }^{1}$ on organizational attractiveness is moderated by applicants' characteristics. Specifically, we will investigate whether applicants will be more vs less attracted to an employing organization they perceive to have traits similar vs dissimilar to their own personality traits. Hereby, applicant personality traits are operationalized in terms of the Big Five personality framework.

\section{The Big Five personality traits}

The lexical hypothesis concerning human personality traits puts forward that all dimensions on which individuals differ and that are used to describe people's behavior or character in daily life, have been captured in the natural language (Cattell, 1943). In addition, the number of expressions in language for a particular trait can be seen as an indicator of the importance of that trait (De Raad, 2000). In this line of research, both Fiske (1949) and Tupes and Christal (1961) were the first to condense thousands of trait adjectives into five broad categories. These are called the 'Big Five' personality dimensions, and have been named Extraversion, Agreeableness, Conscientiousness, Neuroticism, and Openness to Experience. Together they represent the fivefactor model of personality.

During the past decades, the five-factor model has proven to be robust (Barrick \& Mount, 1991). The Big Five personality dimensions have indeed been identified using different instruments (Costa \& McCrae, 1988), in different cultures (Noller, Law, \& Comrey, 1987), and using ratings obtained from different sources (McCrae \& Costa, 1987). Moreover, the Big Five are acknowledged to capture most of the variance in personality (Costa \& McCrae, 1992). As is common in the field of personality psychology, each of the Big Five is defined by several facets that reflect specific sides or aspects of the broader factors.

Aaker (1997) poses that three brand personality dimensions may relate to three of the Big Five human personality dimensions. More specifically, she argues that Agreeableness, Extraversion, and Conscientiousness may tap on Sincerity, Excitement, and Competence, respectively. Agreeableness is defined by traits as courteous, flexible, trusting, good-natured, cooperative, forgiving, soft-hearted, and tolerant (Barrick \& Mount, 1991). According to Aaker (1997), 'Agreeableness and Sincerity both capture the idea of warmth and 
acceptance' (p. 353). Preliminary support for the overlap between the two comes from a study by Ashton, Lee, and Son (2000) who found correlations in the range of .40-.50 between the personality factor 'Honesty' (i.e., sincerity, trustworthiness, integrity) and several Agreeableness facets (i.e., straightforwardness, compliance, trust).

Traits associated with Extraversion include being sociable, gregarious, assertive, talkative, and active (Barrick \& Mount, 1991). Furthermore, according to Costa and McCrae (1992), one facet of Extraversion, called Excitement-Seeking, is intended to measure sensation seeking (i.e., 'the need for varied, novel, and complex sensations and experiences and the willingness to take physical and social risks for the sake of such experience' (Zuckerman, 1979, p. 10). Not surprisingly, positive correlations have been reported among the personality traits Extraversion and Sensation-Seeking (e.g., Aluja, Garcia, \& Garcia, 2003; Zuckerman \& Bone, 1972). Similarly, Aaker (1997) argues that Extraversion may overlap with the brand personality trait Excitement because 'both connote the notions of sociability, energy, and activity' (p. 353).

Common traits associated with Conscientiousness include being careful, thorough, responsible, organized, planful, hardworking, achievement-oriented, and persevering (Barrick \& Mount, 1991). According to Costa and McCrae's (1992) conceptualization of Conscientiousness, competence is one of the six facets of this trait. As a facet, competence refers to one's sense of being capable, effective, and sensible. Other Conscientiousness facets that bear clear resemblance to Competence as a symbolic trait (described by terms as reliable, secure, intelligent, and successful) are self-discipline (the ability to begin tasks and carry them through to completion despite boredom and other distractions), and deliberation (i.e., impulse control, patience, and maturity). According to Aaker (1997), Conscientiousness and the brand personality trait Competence both encapsulate responsibility, dependability, and security.

To the best of our knowledge, these three stated correspondences have not yet been empirically tested, despite their compelling logic. Therefore, based on the above arguments and relying on principles from the similarity-attraction framework, we put forward the following hypotheses:

Hypothesis 1: Agreeableness will moderate the relationship between Sincerity and organizational attractiveness, such that this relationship will be stronger for individuals high on Agreeableness>

Hypothesis 2: Extraversion will moderate the relationship between Excitement and organizational attractiveness, such that this relationship will be stronger for individuals high on Extraversion.
Hypothesis 3: Conscientiousness will moderate the relationship between Competence and organizational attractiveness, such that this relationship will be stronger for individuals high on Conscientiousness.

In our opinion, however, more hypotheses can be formulated about correspondences between human and organizational personality traits. For example, further inspection of the human personality factor Conscientiousness reveals the facet dutifulness (McCrae \& Costa, 2003), which reflects the propensity to honor and uphold commitments to social justice and social obligations (Roberts, Chernyshenko, Stark, \& Goldberg, 2005). This aspect of Conscientiousness is clearly linked with the facets honest and sincere, which partly define the organizational personality factor Sincerity. Moreover, both the human and organizational personality trait have a strong link with integrity (Hosmer, 1995; Ones, 1993), which is the most valid personality predictor of job performance (Schmidt \& Hunter, 1998). Relying on principles from the similarity-attraction framework, we put forward the following hypothesis:

Hypothesis 4: Conscientiousness will moderate the relationship between Sincerity and organizational attractiveness, such that this relationship will be stronger for individuals high on Conscientiousness.

People high on Openness to Experience, another factor of the Big Five, also tend to score high on sensation seeking (Garcia, Aluja, Garcia, \& Cuevas, 2005). Both concepts are defined by the need for novel sensations and the search for exciting and unusual activities and experiences (Costa \& McCrae, 1992; Zuckerman, 1979). People high on Openness are described as daring, adventurous, bored by familiarity, and stifled by routine. Returning to organizational personality, we see a clear resemblance between Openness to Experience and the symbolic factor Excitement, characterized by the adjectives exciting, daring, and thrilling (Lievens et al., 2005). Relying on principles from the similarityattraction framework, we put forward the following hypothesis:

Hypothesis 5: Openness to Experience will moderate the relationship between Excitement and organizational attractiveness, such that this relationship will be stronger for individuals high on Openness.

Individuals high on Openness to Experience have analytic minds, are broad-minded and attracted to new ideas. They are mainly focused on intangible ideas, fantasies, experiences, and culture (McCrae \& Costa, 1997). In contrast, rugged organizations have been defined by the facets masculine, tough, and rugged, which suggest a connection with physical and visible 
attributes of people. Further evidence for this contrast between high Openness and Ruggedness is provided by the resemblance between low Openness and authoritarian features like favoring conservative values and sex-role stereotyped behavior (McCrae, Costa, \& Busch, 1986). Again, relying on principles from the similarity-attraction framework, we put forward the following hypothesis:

Hypothesis 6: Openness to Experience will moderate the relationship between Ruggedness and organizational attractiveness, such that this relationship will be stronger for individuals low on Openness.

Concerning the human personality factor Neuroticism, and the organization personality factor Sophistication (Prestige), no hypotheses were formulated.

\section{Method}

\subsection{Context}

In the present study, the above-mentioned hypotheses were tested by using the military as the referent organization. This military context is relevant for two reasons. First, military organizations are among the largest employers, hiring hundreds, if not thousands, of people every year. The high recruitment demands, however, have become a heavy burden for the military mainly due to economic and demographic changes. Militaries in several nations are increasingly facing difficulties in attracting, enlisting, and retaining the required numbers of new recruits (Asch, Hosek, Arkes, Fair, Sharp, \& Totten, 2002; Bachman, Segal, FreedmanDoan, \& O'Malley, 2000; Knowles, Parlier, Hoscheit, Ayer, Lyman, \& Fancher, 2002). In addition, in many European countries, the importance of attracting new recruits has been bolstered by the transition to a voluntary military service (Lescreve, 2000). Second, in order to test the hypotheses, subjects must have at least some basic level of awareness of the referent organization (Cable \& Turban, 2001). Without any prior knowledge of an organization it is impossible to meaningfully ascribe personality trait-based characteristics to the organization. The military, having a strong and distinctive image as an employer (Lievens et al., 2007), can be reasonably assumed to be known among the study subjects and, therefore, seems an appropriate candidate to act as referent organization.

\subsection{Participants and procedure}

To study applicant attraction in an early recruitment phase, it is paramount to sample from the target population (Lievens et al., 2005). As the military pri- marily recruits high school students ready to enter the labor market (Bachman et al., 2000; Schreurs, Derous, De Witte, Proost, Andriessen, \& Glabeke, 2005; Segal, Burns, Falk, Silver, \& Sharda, 1998), we decided to sample from this population. In particular, our sample consisted of 370 final-year students of Belgian high schools. Care was taken to ensure that all types of high schools were included and that the sample of high schools was geographically dispersed. We visited these schools and explained that the purpose of the study was to examine the attractiveness of the armed forces. Students were given about 2 weeks to complete the surveys. Participation in the study was voluntary and anonymous. Completed surveys were collected by the respective teachers and sent back to us. We received complete and usable responses from 245 students $(42 \%$ women; mean age $=17.96$ years, $S D=.88$ year, range $=17-23$ years), yielding a response rate of $66 \%$.

\subsection{Measures}

All self-report measures in this study were retrieved from existing studies and utilized a five-point Likert scale $(1=$ strongly disagree to $5=$ strongly agree).

\subsubsection{Big Five personality traits}

The Big Five personality traits were measured with the NEO Five Factor Inventory ${ }^{2}$ (NEO-FFI, Costa \& McCrae, 1992). The NEO-FFI is a shorter version of the Revised NEO Personality Inventory, and it contains five subsections that, respectively, assessed the factors of Neuroticism, Extraversion, Openness to Experience, Agreeableness, and Conscientiousness. There are 12 items per subsection, for a total of 60 items. A sample item from the Extraversion subscale is "I like to have a lot of people around me.' Costa and McCrae reported internal consistency coefficients ranging from .68 to .86 and provided extensive validity data. In the present study, internal consistency estimates were a bit lower and ranged from .67 to .77 .

\subsubsection{Symbolic characteristics of the military}

Symbolic characteristics about the armed forces were measured with an instrument previously developed by Lievens et al. (2005). Specifically, in a study on the attractiveness of the military as an employer, Lievens et al. (2005) adapted Aaker's (1997) instrument for measuring symbolic attributes related to brands to fit the military context. Aaker's measure contains five broad dimensions of brand personality: Sincerity, Excitement, Competence, Sophistication (or Prestige), and Ruggedness. Lievens et al. $(2005,2007)$ found that five similar factors can be used to describe the personality of the armed forces: Sincerity (i.e., honest, sincere, down-toearth), Excitement (i.e., daring, exciting, thrilling), Com- 
petence (i.e., intelligent, technical, corporate), Prestige (i.e., high status, highly regarded, well respected), and Ruggedness (i.e., tough, rugged, masculine). Similar to Lievens et al. (2005, 2007), in the present study, respondents were asked to ascribe these traits to the military. The reliabilities of Sincerity, Excitement, Competence, Prestige, and Ruggedness were $\alpha=.77, .89$, $.67, .71, .83$, respectively.

Given that the Lievens et al. (2005) measure is relatively new, we conducted a confirmatory factor analysis using LISREL 8.54 to verify the fit of the fivedimensional conceptualization. This analysis showed a good fit for a five-factor solution: $\chi^{2}(80$, $N=245)=129.47, p<.001 ; \chi^{2} / d f=1.61$; root-meansquare residual $(\mathrm{RMSR})=.05$; comparative fit index $=.98$; incremental fit index $=.98$. The average standardized item loadings onto each of the factors were as follows: Sincerity $=.75$, Excitement $=.86$, Competence $=.63$, Prestige $=.67$, Ruggedness $=.80$. These results provide some support for the fivedimensional structure used in this study.

\subsubsection{Organizational attractiveness}

Organizational attractiveness was measured with three items from Highhouse, Lievens, and Sinar (2003). This scale assessed applicants' attitudes toward the organization as a potential place for employment. A sample item is, 'For me, the military would be a good place to work.' The reliability of the organizational attractiveness scale was .90 .

\subsubsection{Control variables}

Respondents were asked to fill out their age, gender ( 0 =male, $1=$ female), and educational background ( 0 = technical/professional school, $1=$ general secondary school). They were also asked whether someone in their family works for the armed forces $(0=$ no,
$1=$ yes). These variables were included because prior research on military propensity and enlistment of high school seniors has shown their importance (Bachman et al., 2000; Lievens et al., 2005; Mael \& Ashforth, 1995).

\section{Analyses and results}

\subsection{Descriptive statistics}

Table 1 presents the reliabilities, means, standard deviations, and correlations among the study variables. As is shown in Table 1, all organizational personality factors showed a significant positive correlation with organizational attractiveness, ranging from .13 (Ruggedness) to .47 (Prestige). Although Ruggedness was ascribed to the armed forces more than any other of the symbolic trait inferences $(M=3.58)$, it yielded the lowest correlation with organizational attractiveness $(r=.13)$. The trait inference attributed the least to the military was Prestige $(M=2.67)$, which, on the other hand, showed the highest correlation with organizational attractiveness $(r=.47)$. Looking at the Big Five, two factors showed a significant correlation with organizational attractiveness, namely Openness to Experience $(r=-.32)$ and Conscientiousness $(r=.13)$.

\subsection{Test of hypotheses}

We conducted hierarchical moderated multiple regression analyses to test the hypotheses. We centered the predictor variables before conducting the analyses to minimize the influence of multicollinearity among the interactions and main effects (Cohen, Cohen, West, \& Aiken, 2003). The resulting standardized regression coefficients are presented in Table 2.

Table 1. Means, standard deviations, and correlations among study variables

\begin{tabular}{|c|c|c|c|c|c|c|c|c|c|c|c|c|c|c|c|c|}
\hline & $M$ & $S D$ & 1 & 2 & 3 & 4 & 5 & 6 & 7 & 8 & 9 & 10 & 11 & 12 & 13 & 15 \\
\hline Gender & .42 & .49 & & & & & & & & & & & & & & \\
\hline Age & 17.93 & .88 & $-.32 * *$ & $=$ & & & & & & & & & & & & \\
\hline Education & .43 & .50 & $.47^{* *}$ & $-.18^{* *}$ & $=$ & & & & & & & & & & & \\
\hline Family & .33 & .47 & .05 & .01 & -.10 & - & & & & & & & & & & \\
\hline Sincerity & 3.00 & .90 & -.12 & -.06 & -.03 & .05 & $(.77)$ & & & & & & & & & \\
\hline Prestige & 2.67 & .91 & $-.26 * *$ & -.02 & -.10 & .09 & $.44 * *$ & * $(.71)$ & & & & & & & & \\
\hline Excitement & 3.35 & .98 & -.04 & -.02 & -.03 & .10 & $.27^{* *}$ & k. $.41^{* *}$ & $(.89)$ & & & & & & & \\
\hline Competence & 3.23 & .78 & -.10 & -.01 & .04 & .05 & $.43 * *$ & k. $.40 * *$ & $.47^{* * *}$ & $(.67)$ & & & & & & \\
\hline Ruggedness & 3.44 & .96 & -.00 & -.01 & .02 & -.01 & $.23 * *$ & $.29 * *$ & $.40 * *$ & $=.27 * *$ & $(.83)$ & & & & & \\
\hline Neuroticism & 2.89 & .53 & .09 & -.04 & .01 & -.10 & .07 & -.03 & .05 & -.05 & -.00 & $(.76)$ & & & & \\
\hline Extraversion & 3.60 & .52 & .05 & .04 & -.08 & .11 & .01 & -.01 & $.14^{*}$ & .06 & .07 & $-.34 * *$ & $(.77)$ & & & \\
\hline $\begin{array}{l}\text { Openness to } \\
\text { Experience }\end{array}$ & 3.03 & .49 & $.19 * *$ & -.02 & .10 & .02 & $-.23 * *$ & $-.25 * *$ & $-.21 *$ & $-.14^{*}$ & $-.15^{*}$ & -.01 & -.04 & (.67) & & \\
\hline Agreeableness & 3.31 & .44 & $.14^{*}$ & -.04 & .10 & -.07 & -.01 & -.11 & -.02 & .05 & -.03 & $-.19 * *$ & $.31^{* *}$ & .10 & $(.68)$ & \\
\hline Conscientiousness & 3.41 & .48 & -.03 & .07 & -.12 & .10 & .06 & $.14^{*}$ & .10 & .13 & -.03 & -.07 & $.21^{* *}$ & -.02 & $.29 * *$ & $=(.73)$ \\
\hline $\begin{array}{l}\text { Organizational } \\
\text { attractiveness }\end{array}$ & 2.52 & 1.22 & $-.37 * *$ & $=.13 *$ & $-.31 * *$ & .08 & $.34 * *$ & $.47^{* * *}$ & $.24 * *$ & $.32 * *$ & .07 & -.06 & .07 & $-.32 * *$ & -.12 & $.13^{*}(.90)$ \\
\hline
\end{tabular}

Note. Alpha reliabilities are in brackets on the diagonal. ${ }^{*} p<.05$. ${ }^{*} *_{p}<.01$. 
Table 2. Results for the moderated regression analyses for organizational attractiveness ${ }^{\mathrm{a}}$

\begin{tabular}{|c|c|c|c|c|}
\hline & \multicolumn{4}{|c|}{ Organizational attractiveness } \\
\hline & Step 1 & Step 2 & Step 3 & Step 4 \\
\hline \multicolumn{5}{|l|}{ Step 1: Control variables } \\
\hline Gender & $-.30 * * *$ & $-.25 * * *$ & $-.15^{*}$ & $-.15^{*}$ \\
\hline Age & .00 & .00 & .05 & .06 \\
\hline Education & $-.16^{*}$ & $-.13^{*}$ & $-.18^{* *}$ & $-.19 * *$ \\
\hline Family & .08 & .06 & .02 & .05 \\
\hline \multicolumn{5}{|c|}{ Step 2: Main effects of Big Five personality traits } \\
\hline Neuroticism & & -.03 & -.03 & -.04 \\
\hline Extraversion & & .06 & .07 & .07 \\
\hline Openness to experience & & $-.24 * * *$ & $-.16^{* *}$ & $-.13^{*}$ \\
\hline Agreeableness & & -.10 & -.08 & -.10 \\
\hline Conscientiousness & & .11 & .04 & .05 \\
\hline \multicolumn{5}{|c|}{ Step 3: Main effects of Symbolic trait inferences } \\
\hline Sincerity & & & $.13^{*}$ & .10 \\
\hline Prestige & & & $.26 * * *$ & $.25 * * *$ \\
\hline Excitement & & & .00 & .00 \\
\hline Competence & & & $.15^{*}$ & $.15^{*}$ \\
\hline Ruggedness & & & -.09 & -.06 \\
\hline \multicolumn{5}{|l|}{ Step 4: Hypothesized 2-way interactions } \\
\hline Sincerity $\times$ Agreeableness & & & & -.08 \\
\hline Excitement $\times$ Extraversion & & & & -.07 \\
\hline Competence $\times$ Conscientiousness & & & & .04 \\
\hline Sincerity $\times$ Conscientiousness & & & & $.16 * *$ \\
\hline Excitement $\times$ Openness & & & & $.14^{*}$ \\
\hline Ruggedness $\times$ Openness & & & & -.02 \\
\hline$\Delta R^{2}$ & & $.08 * * *$ & $.14 * * *$ & $.04 *$ \\
\hline Total Adjusted $R^{2}$ & $.16 * * *$ & $.22 * * *$ & $.35 * * *$ & $.38 * * *$ \\
\hline
\end{tabular}

Note. ${ }^{a}$ The standardized regression coefficients are presented. ${ }^{*} p<.05 . *^{* *} p<.01 . * * *<.001$.

We entered at step 1 the control variables - gender, age, type of education, and military history in family. They accounted for a significant amount of variance in organizational attractiveness $\left(R^{2}=.17, p<.001\right.$; total adjusted $\left.R^{2}=.16, p<.001\right)$. Gender $(\beta=-.30, p<.001)$ and educational level $(\beta=-.16, \quad p<.05)$ were significant predictors of attractiveness. At step 2, we entered the main effects of the Big Five personality traits - Neuroticism, Extraversion, Openness to Experience, Agreeableness, and Conscientiousness. Their addition contributed unique variance $\left(\Delta R^{2}=.08, p<.001\right.$; total adjusted $\left.R^{2}=.22, p<.001\right)$. Only the coefficient of Openness to Experience was significant $(\beta=-.24, p<.001)$. We entered the main effects of symbolic trait inferences at step 3. They added incremental variance over-and-above the variance accounted for by the control variables and the main effects of the Big Five personality traits $\left(\Delta R^{2}=.14\right.$, $p<.001$; total adjusted $\left.R^{2}=.35, p<.001\right)$. The coefficients of Sincerity $(\beta=.13, p<.05)$, Prestige $(\beta=.26$, $p<.001)$, and Competence $(\beta=.15, p<.05)$ were significant. We entered the set of two-way interactions at step 4 . They accounted for significant incremental variance in organizational attractiveness over-and-above the variance explained by the controls and the main effects $\left(\Delta R^{2}=.04, p<.05 ;\right.$ total adjusted $\left.R^{2}=.38, p<.001\right)$. The Sincerity $\times$ Conscientiousness $(\beta=.16, p<.01)$ and Excitement $\times$ Openness $(\beta=.14, p<.05)$ interaction terms added significant variance providing support for Hypotheses 4 and 5 . Thus, the results were inconsistent with Hypotheses 1, 2, 3, and 6.

We followed Aiken and West's (1991) procedure to graphically depict the forms of the significant interactions. Figures 1 and 2 present the plots of the Sincerity $\times$ Conscientiousness and Excitement $\times$ Openness interactions, respectively. Figure 1 indicates that Sincerity is positively related to organizational attractiveness only for individuals who are at the high end of Conscientiousness $(t=3.00, p<.01)$. Conversely, for people low on Conscientiousness, Sincerity shows no connection with organizational attractiveness $(t=-.45$, NS). Figure 2 indicates that the relationship between Excitement and organizational attractiveness is opposite, depending on the personality trait Openness to Experience: for prospective applicants high on Openness this relationship is more positive than for prospective applicants low on this trait. Both slopes did not differ significantly from zero $(t=1.43$, NS and $t=-1.26$, NS, respectively), only significantly from each other.

\section{Discussion}

Recently, recruitment scholars (Lievens \& Highhouse, 2003; Slaughter et al., 2004) have shown that prospec- 


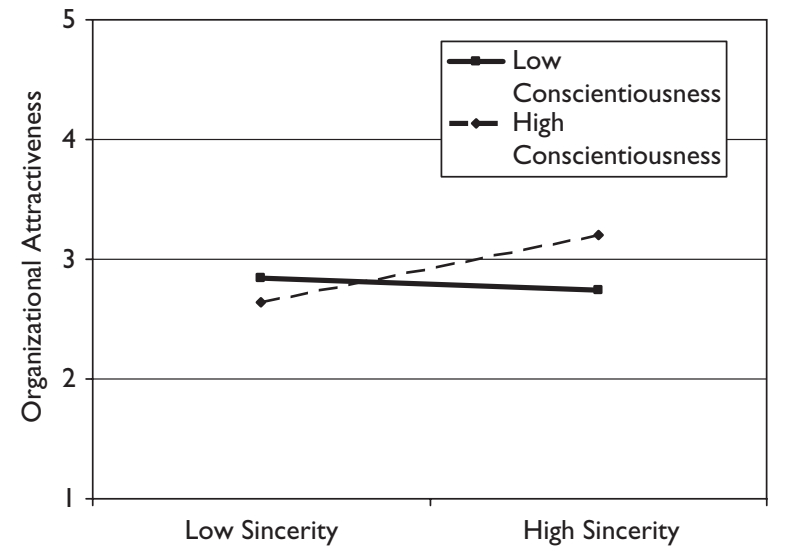

Figure 1. Interactive Effect of Sincerity and Conscientiousness on Organizational Attractiveness.

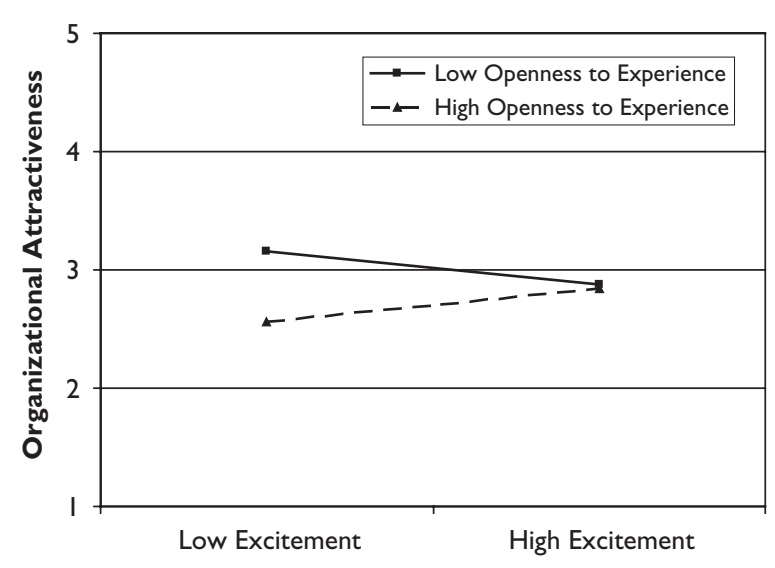

Figure 2. Interactive Effect of Excitement and Openness to Experience on Organizational Attractiveness.

tive applicants ascribe human personality traits (also referred to as symbolic attributes) to organizations and that these symbolic trait-based inferences play an important role in applicants' attractiveness to organizations. The central aim of the present study was to examine the moderating influence of individual differences in the relationship between symbolic, trait-based inferences, and organizational attractiveness. Particularly, the study investigated, for the first time, specific interactions between trait-based inferences and the Big Five personality traits. Drawing on the similarity-attraction paradigm (Byrne, 1971), six hypotheses were formulated, stating that the relationship between trait-based inferences and organizational attractiveness would be stronger for persons who perceive the organization as similar to themselves.

Moderated regression analysis revealed two significant two-way interactions, showing that the trait inference Sincerity is positively related to organizational attractiveness only for individuals high on Conscientiousness, and that the relationship between the trait inference Excitement and organizational attractiveness is more positive for individuals high (relative to low) on Openness to Experience. These significant results support the basic tenet of the interactionist perspective (Turban \& Keon, 1993) that individuals differ in their attraction to job and organizational characteristics depending on their own personality. Furthermore, these results extend previous research by demonstrating that individuals are not only differentially attracted to tangible, instrumental characteristics, such as pay preferences (e.g., Cable \& Judge, 1994), organizational size (e.g., Turban \& Keon, 1993), and level of centralization (e.g., Lievens et al., 2001), but also to symbolic, trait-based characteristics.

In addition to the interactionist similarity-attraction paradigm, alternate theoretical mechanisms may account for the observed moderating effect of Conscientiousness. For instance, research has shown that conscientious individuals pay more attention to situational cues than their nonconscientious counterparts (e.g., Miron, Erez, \& Naveh, 2004). Vicarious learning theory (Bandura, 1977) suggests that individuals who pay more attention to details are more likely to learn. Hence, it is possible that the effect of Sincerity on organizational attractiveness is stronger for high conscientious individuals because they have been more attentive and respond correspondingly. ${ }^{3}$ Further research is necessary to examine which theoretical framework is more appropriate to explain the observed relationships.

Furthermore, it is important to note that most of the hypothesized interactions were not supported. No evidence was found for the three hypotheses borrowed from Aaker (1997). She was the first to suggest that the trait inferences Sincerity, Excitement, and Competence could feasibly map on to the Big Five personality factors Agreeableness, Extraversion, and Conscientiousness, respectively. In later research (e.g., Lievens \& Highhouse, 2003; Lievens et al., 2005), these assumed equivalences were echoed, but, to our knowledge, never empirically tested in relation to organizational attractiveness. Because all the study hypotheses were mainly grounded in a set of conceptual and logical considerations, a possible explanation for the null-findings is that the conceptual overlap between the human and organizational personality dimensions is too small to lead to attraction on the basis of similarity. For example, even if Sincerity and Agreeableness share the notion of warmth and acceptance (Aaker, 1997), they are probably dissimilar with respect to other associations. To illustrate, in Aaker's study Sincerity is described by traits such as small-town, sentimental, down-to-earth, and wholesome, traits that are typically not associated with Agreeableness. The same reasoning may hold for the dyads CompetenceConscientiousness, and Excitement-Extraversion. Taken together, these findings indicate that organizational personality and human personality are not as easily matched as is widely assumed, and - $a$ fortiori - that the structure 
of organizational personality traits does not necessarily correspond to the human taxonomy in terms of the 'Big Five' (see also Slaughter et al., 2004). This finding contradicts earlier untested assumptions made by recruitment scholars (e.g., Lievens \& Highhouse, 2003; Lievens et al., 2005) - thereby extending our knowledge about the (dis)similarities between human and organizational personality.

The non-significant results might also be attributed to a lack of power to detect moderator effects in observational studies. McClelland and Judd (1993) show that field studies, relative to experiments, have nonoptimal distributions of the independent variables, which implies that the residual variance of the product term of these variables is relatively lower. This, in turn, means that the efficiency of the moderator parameter estimate and statistical power are much lower, possibly too low to detect an interaction of a small effect size in the population. Moreover, working with less than perfectly reliable predictors results in an even more unreliable product term, again lowering the power to detect the interaction term, relative to the power to detect the first-order effects (Cohen et al., 2003). However, we admit that these are only speculations as to why four of the hypothesized interactions did not reach the significance level.

The present study is an interaction study, investigating the moderating role of prospective applicants' personality in the relationship between organizational personality, in terms of symbolic attributes, and organizational attractiveness. Previous studies framed the attractiveness of organizations for prospective applicants in the context of the fit between the person and organization (P-O fit, e.g., Bretz \& Judge, 1994; Cable \& Judge, 1994; Lievens et al., 2001). Based on recent recommendations by Kristof-Brown, Zimmerman, and Johnson (2005), we were reluctant to do so. These authors excluded all $\mathrm{P}-\mathrm{O}$ interaction studies from their meta-analysis on person-environment fit because 'moderator studies rarely conceptualize the person and organization on commensurate dimensions. Without this standard it is impossible to directly compare Person and Environment (PE) values, a fundamental property of the P-E fit theory' (p. 284). Based on the results from the present study and previous research in this area (Slaughter et al., 2004), it seems that the structure of organizational personality does not completely correspond to the human taxonomy, and that therefore, strictly speaking, the $\mathrm{P}-\mathrm{O}$ fit nomenclature is not appropriate.

\subsection{Limitations and future research}

This study is not without limitations. First, prospective applicants were asked to rate only one organization.
Not only does this seem in contrast with applicants' actual behavior, considering several employers over a longer period of time, it might also be argued that, from a measurement-theoretical perspective, differences in perceptions across respondents reflect deviations from some 'true' personality of the military. However, the objective of this study was not to evaluate the actual personality of the military, but rather to examine how idiosyncratic impressions of Army personality interact with individual personality to determine organizational attractiveness.

Second, the results are based on cross-sectional selfreports collected by a single survey. Therefore, common method variance (e.g., due to consistency effects) may be of concern. It seems unlikely, however, that this same-source method bias is an alternative explanation for our results, because many of the correlations found were low or non-significant. Furthermore, confirmatory factor analysis provided support for the construct validity of the measures used.

A third limitation relates to the generalizability of our results. Our study was conducted with the Belgian armed forces as a referent organization. As symbolic attributes are derived specific to organizations (Lievens \& Highhouse, 2003), in the present study a tailoredmade measure of symbolic attributes was used, that was formerly developed for the military (Lievens et al., 2005). It is very likely, however, that the attributes that emerged in the present study are not descriptive of organizations in other countries, cultures, and industries. Furthermore, a potential boundary condition to generalizability is that the military typically has a strong and distinctive image as an employer (Lievens, 2007). That is, individuals may have more divergent opinions about the military than they have about other organizations. Because most studies employing the instrumental-symbolic framework have been conducted in a military setting, it is yet unclear whether symbolic attributes are equally important in predicting attraction to organizations with a less distinctive image. It may even be that instrumental job and organizational attributes wash out symbolic attributes in organizations other than the military. For all these reasons, we recommend future investigations to explore the relationships between instrumental and symbolic attributes, potential applicants' personality, and organizational attractiveness in other settings and with other instruments (e.g., Slaughter et al., 2004).

A final direction for future research which we believe holds promise is to differentiate between the trait inferences of organizations and of jobs within that organization. Obviously, the perceived personalities of a job (e.g., accountant) and organization (e.g., military) can differ substantially. Which trait inferences carry most weight in determining applicant attraction then? Also, job analyses have been extended to assess per- 
sonality requirements of the job. What if the traits identified in a job analysis are different from the personality of the organization? These and related questions may form the basis of useful future research.

\subsection{Practical implications}

The results suggest that the effect of recruitment activities and campaigns may differ according to the characteristics of the prospective applicant population. Therefore, we recommend that all activities displaying corporate image are carefully tailored to target prospective applicants with desirable personality traits. For instance, as Conscientiousness is a valid predictor of job performance and training proficiency (Barrick, Mount, \& Judge, 2001), this seems a highly wanted personality trait for recruits, and applicants in general. A campaign projecting the organization as sincere could be a possible means of reaching these applicants. Nonetheless, caution is prescribed here; discrepancies between the projected image and the organizational reality could also lead to dysfunctional turnover.

In this light, it might be of enormous value to an organization to assess its personality, as perceived by outsiders, potential applicants and/or actual personnel. Any incongruity between the perception of actual personnel and that of outsiders or applicants might be corrected by appropriate (recruitment) campaigns. Additionally, our findings suggest that recruitment activities best focus on individuals with a personality that is similar to the perceived organizational personality, so as to attract more applicants. Moreover, the congruence between a subjects' personality and the organizational personality has previously been found to be associated with a higher likelihood to stay in the organization (e.g., Hoffman \& Woehr, 2006; Verquer, Beehr, \& Wagner, 2003).

In sum, our results indicate that applicants are differentially attracted by organizational personality, in function of their own personality. Therefore, it might be valuable for organizations to evaluate the personality they project, and to tailor recruitment campaigns to attract specific applicant personalities.

\section{Acknowledgement}

We would like to acknowledge Tom Welkenhuysen for assisting in data collection.

\section{Notes}

1. Note that we consider symbolic attributes as a set of human personality characteristics perceived to be asso- ciated with an organization. We are not suggesting that organizations 'have' personalities in the sense that humans have personalities. Nor do we treat organizations as if they were living, breathing entities with predictable behavioral tendencies. Rather, in the present study, organizational personality emanates from perceptions of individuals who are - to some extent - familiar with the organization.

2. We used the NEO-FFI - the short form of the NEO-PI-R - because for some schools, in order to participate in the study, it was required that the questionnaire would not be too lengthy. As the NEO-FFI does not provide facet scores, we were unable to match facet scales with symbolic attributes, or to combine facets across the Big Five to match the personality assessments of the military. As noted by a reviewer, this might be an interesting direction for further research.

3. We thank an anonymous reviewer for suggesting this alternative explanation.

\section{References}

Aaker, J.L. (1997) Dimensions of Brand Personality. Journal of Marketing Research, 34, 347-356.

Aaker, J.L. (1999) The Malleable Self: The role of self-expression in persuasion. Journal of Marketing Research, 36, 45-57.

Aiken, L.S. and West, S.G. (1991) Multiple Regression: Testing and interpreting interactions. Newbury Park, CA: Sage.

Aluja, A., Garcia, O. and Garcia, L.F. (2003) Relationships Among Extraversion, Openness to Experience, and Sensation Seeking. Personality and Individual Differences, 35, 671680.

Asch, B., Hosek, J.R., Arkes, J., Fair, C., Sharp, J. and Totten, M. (2002) Military Recruiting and Retention after the Fiscal Year 2000 Pay Legislation. Santa Monica, CA: RAND.

Ashton, M.C., Lee, K. and Son, C. (2000) Honesty as the Sixth Factor of Personality: Correlations with Machiavellianism, primary psychopathy, and social adroitness. European Journal of Personality, 14, 359-368.

Bachman, J.G., Segal, D.R., Freedman-Doan, P. and O'Malley, P.M. (2000) Who Chooses Military Service? Correlates of Propensity and Enlistment in the U.S. Armed Forces. Military Psychology, 12, 1-30.

Bandura, A. (1977) Social Learning Theory. Englewood Cliffs, NJ: Prentice-Hall.

Barrick, M.R. and Mount, M.K. (1991) The Big Five Personality Dimensions and Job Performance: A meta-analysis. Personnel Psychology, 44, 1-26.

Barrick, M.R., Mount, M.K. and Judge, T.A. (2001) Personality and Job Performance at the Beginning of the New Millennium: What do we know and where do we go next? International Journal of Selection and Assessment, 9, 9-30.

Bretz, R.D., Ash, R.A. and Dreher, G.F. (1989) Do People Make the Place? An examination of the attraction-selection-attrition hypothesis. Personnel Psychology, 42, 561-581.

Bretz, R.D. and Judge, T.A. (1994) The Role of Human Resource Systems in Job Applicant Decision Processes. Journal of Management, 20, 531-551.

Byrne, D. (1971) The Attraction Paradigm. New York: Academic Press. 
Cable, D.M. and Graham, M.E. (2000) The Determinants of Job Seekers' Reputation Perceptions. Journal of Organizational Behavior, 21, 929-947.

Cable, D.M. and Judge, T.A. (1994) Pay Preferences and Job Search Decisions: A person-organization fit perspective. Personnel Psychology, 47, 317-348.

Cable, D.M. and Judge, T.A. (1996) Person-Organization Fit, Job Choice Decisions, and Organizational Entry. Organizational Behavior and Human Decision Processes, 67, 294-311.

Cable, D.M. and Turban, D.B. (2001) Establishing the Dimensions, Sources and Value of Job Seekers' Employer Knowledge During Recruitment. Research in Personnel and Human Resources Management, 20, 115-163.

Cattell, R.B. (1943) The Description of Personality: Basic traits resolved into clusters. Journal of Abnormal and Social Psychology, 38, 476-507.

Chatman, J.A. (1989) Improving Interactional Organizational Research: A model of person-organization fit. Academy of Management Review, 14, 333-349.

Cohen, J., Cohen, P., West, S.G. and Aiken, L.S. (2003) Applied Multiple Regression/Correlation Analysis for the Behavioral Sciences (3rd edn). Mahwah, NJ: Lawrence Erlbaum.

Costa, P.T. and McCrae, R.R. (1988) From Catalog to Classification: Murray's needs and the five factor model. Journal of Personality and Social Psychology, 55, 258-265.

Costa, P.T. and McCrae, R.R. (1992) Revised NEO Personality Inventory (NEO-PI-R) and NEO Five Factor Inventory (NEO-FFI) Professional Manual. Odessa, FL: Psychological Assessment Resources.

De Raad, B. (2000) The Big Five Personality Factors. The psycholexical approach. Gottingen, The Netherlands: Hogrefe \& Huber Publishers.

Ehrhart, K.H. and Ziegert, J.C. (2005) Why are Individuals Attracted to Organizations? Journal of Management, 31, 901-919.

Fiske, D.W. (1949) Consistency of the Factorial Structures of Personality Ratings from Different Sources. Journal of Abnormal and Social Psychology, 44, 329-344.

Garcia, L.F., Aluja, A., Garcia, O. and Cuevas, L. (2005) Is Openness to Experience an Independent Personality Dimension? Convergent and Discriminant Validity of the Openness Domain and its NEO-PI-R Facets. Journal of Individual Differences, 26, 132-138.

Highhouse, S., Lievens, F. and Sinar, E.F. (2003) Measuring Attraction to Organizations. Educational and Psychological Measurement, 63, 986-1001.

Highhouse, S., Thornbury, E.E. and Little, I.S. (2007) Social-Identity Functions of Attraction to Organizations. Organizational Behavior and Human Decision Processes, 103, 134-146.

Highhouse, S., Zickar, M.J., Thorsteinson, T.J., Stierwalt, S.L. and Slaughter, J.E. (1999) Assessing Company Employment Image: An example in the fast-food industry. Personnel Psychology, 52, 151-172.

Hoffman, B.J. and Woehr, D.J. (2006) A Quantitative Review of the Relationship Between Person-Organization Fit and Behavioral Outcomes. Journal of Vocational Behavior, 68, 389-399.

Hosmer, L.T. (1995) Trust: The connecting link between organizational theory and philosophical ethics. Academy of Management Review, 20, 379-403.
Judge, T.A. and Bretz, R.D. (1992) Effects of Work Values on Job Choice Decisions. Journal of Applied Psychology, 77, 261271.

Judge, T.A. and Cable, D.M. (1997) Applicant Personality, Organizational Culture, and Organization Attraction. Personnel Psychology, 50, 359-394.

Katz, D. (1960) The Functional Approach to the Study of Attitudes. Public Opinion Quarterly, 24, 163-204.

Keller, K.L. (1993) Conceptualizing, Measuring, and Managing Customer-Based Brand Equity. Journal of Marketing, 57, 122.

Keller, K.L. (1998) Strategic Brand Management: Building, measuring, and managing brand equity. Hemel Hempstead: Prentice-Hall International.

Knowles, J.A., Parlier, G.H., Hoscheit, G.C., Ayer, R., Lyman, K. and Fancher, R. (2002) Reinventing Army Recruiting. Interfaces, 32, 78-92.

Kristof-Brown, A.L., Zimmerman, R.D. and Johnson, E.C. (2005) Consequences of Individuals' Fit at Work: A metaanalysis of person-job, person-organization, person-group, and person-supervisor fit. Personnel Psychology, 58, 281-342.

Lescreve, F.J. (2000) Recruiting for the Military: A new challenge. Paper Presented at the 42nd Annual Conference of the International Military Testing Association, Edinburgh, UK.

Lewin, K. (1935) A Dynamic Theory of Personality. New York: McGraw-Hill.

Lievens, F. (2007) Employer Branding in the Belgian Army: The importance of instrumental and symbolic beliefs for potential applicants, actual applicants, and military employees. Human Resource Management, 46, 51-69.

Lievens, F. and Highhouse, S. (2003) The Relation of Instrumental and Symbolic Attributes to a Company's Attractiveness as an Employer. Personnel Psychology, 56, 75-102.

Lievens, F., Decaesteker, C., Coetsier, P. and Geirnaert, J. (2001) Organizational Attractiveness for Prospective Applicants: A person-organization fit perspective. Applied Psychology: An International Review, 50, 30-51.

Lievens, F., Van Hoye, G. and Anseel, F. (2007) Organisational Identity and Employer Image: Towards a unifying framework. British Journal of Management, 18, 45-59.

Lievens, F., Van Hoye, G. and Schreurs, B. (2005) Examining the Relationship Between Employer Knowledge Dimensions and Organizational Attractiveness: An application in a military context. Journal of Occupational and Organizational Psychology, 78, 553-572.

Mael, F.A. and Ashforth, B.E. (1995) Loyal from Day One: Biodata, organizational identification, and turnover among newcomers. Personnel Psychology, 48, 309-333.

McClelland, G.H. and Judd, C.M. (1993) Statistical Difficulties of Detecting Interactions and Moderator Effects. Psychological Bulletin, 114, 376-390.

McCrae, R.R. and Costa, P.T. (1987) Validation of the FiveFactor Model of Personality Across Instruments and Observers. Journal of Personality and Social Psychology, 1, 81-90.

McCrae, R.R. and Costa, P.T. (1997) Conceptions and Correlates of Openness to Experience. In Hogan, R., Johnson, J. and Briggs, S. (eds), Handbook of Personality Psychology. (pp. 825-847). San Diego, CA: Academic Press.

McCrae, R.R. and Costa, P.T. (2003) Personality in Adulthood: A five-factor theory perspective (2nd edn). New York: Guilford. 
McCrae, R.R., Costa, P.T. and Busch, C.M. (1986) Evaluating Comprehensiveness in Personality Systems: The California Q-set and the five-factor model. Journal of Personality, 54, 430-446.

Miron, E., Erez, M. and Naveh, E. (2004) Do Personal Characteristics and Cultural Values that Promote Innovation, Quality, and Efficiency Compete or Complement Each Other? Journal of Organizational Behavior, 25, 175-199.

Noller, P., Law, H. and Comrey, A.L. (1987) The Cattell, Comrey, and Eysenck Personality Factors Compared: More evidence for five robust factors? Journal of Personality and Social Psychology, 53, 775-782.

Ones, D.S. (1993) The Construct Validity of Integrity Tests. Unpublished doctoral dissertation, University of lowa City, lowa.

O'Reilly, C.A., Chatman, J.A. and Caldwell, D.F. (1991) People and Organizational Culture: A profile comparison approach to person-organization fit. Academy of Management Journal, 34, 487-516.

Roberts, B.W., Chernyshenko, O.S., Stark, S. and Goldberg, L.R. (2005) The Structure of Conscientiousness: An empirical investigation based on seven major personality questionnaires. Personnel Psychology, 58, 103-139.

Rynes, S.L. and Barber, A.E. (1990) Applicant Attraction Strategies: An organizational perspective. Academy of Management Review, 15, 286-310.

Schmidt, F.L. and Hunter, J.E. (1998) The Validity and Utility of Selection Methods in Personnel Psychology: Practical and theoretical implications of 85 years of research findings. Psychological Bulletin, 124, 262-274.

Schreurs, B., Derous, E., De Witte, K., Proost, K., Andriessen, M. and Glabeke, K. (2005) Attracting Potential Applicants to the Military: The effects of initial face-to-face contacts. Human Performance, 18, 105-122.
Segal, D.R., Burns, T.J., Falk, W.W., Silver, M. and Sharda, B.D. (1998) The All-Volunteer Force in the 1970s. Social Science Quarterly, 79, 390-411.

Shavitt, S. (1990) The Role of Attitude Objects in Attitude Functions. Journal of Experimental Social Psychology, 26, 124-148.

Slaughter, J.E., Zickar, M.J., Highhouse, S. and Mohr, D.C. (2004) Personality Trait Inferences about Organizations: Development of a measure and assessment of construct validity. Journal of Applied Psychology, 89, 85-103.

Steele, C.M. (1988) The Psychology of Self-Affirmation: Sustaining the integrity of the self. Advances in Experimental Social Psychology, 21, 261-302.

Tajfel, H. and Turner, J. (1986) The Social Identity Theory of Intergroup Behaviour. In Worchel, S. and Austin, W.G. (eds), The Psychology of Intergroup Relations. Chicago: Nelson-Hall, pp. 7-24.

Tupes, E.C. and Christal, R.C. (1961) Recurrent Personality Factors Based on Trait Ratings (USAF ASD Technical Report, No. 61-97), U.S. Air Force, Lackland Air Force Base, TX.

Turban, D.B. and Keon, T.L. (1993) Organizational Attractiveness: An interactionist perspective. Journal of Applied Psychology, 28, 184-193.

Verquer, M.L., Beehr, T.A. and Wagner, S.H. (2003) A MetaAnalysis of the Relationships Between Person-Organization Fit and Work Attitudes. Journal of Vocational Behavior, 63, 473-489.

Zuckerman, M. (1979) Sensation Seeking: Beyond the optimal level of arousal. Hillsdale, NJ: Erlbaum.

Zuckerman, M. and Bone, R.N. (1972) What is the Sensation Seeker? Personality Trait and Experience Correlates of the Sensation-Seeking Scales. Journal of Consulting and Clinical Psychology, 39, 308-321. 